TecnoLógicas

ISSN-p 0123-7799

ISSN-e 2256-5337

Vol. 21, No. 42, pp. $95-110$

Mayo-agosto de 2018

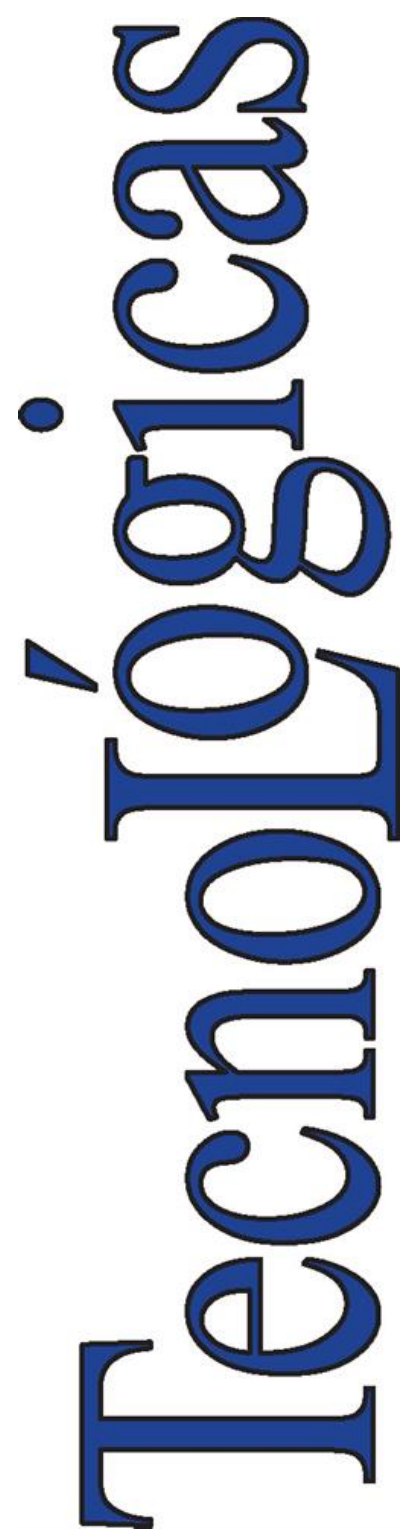

(C) Copyright 2015 por autores y Tecno Lógicas Este trabajo está licenciado bajo una Licencia Internacional Creative Commons Atribución (CC BY)

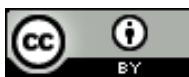

Artículo de Investigación/Research Article

\section{Quasi-switched inverter using space vector pulse width modulation with triangular comparison for photovoltaic applications}

\section{Inversor cuasi-conmutado usando modulación de ancho de pulso del vector espacial con comparación triangular para aplicaciones fotovoltaicas}

\author{
Iván F. Moran ${ }^{1}$, José A. Restrepo ${ }^{2}$, Martha L. Orozco- \\ Gutierrez $^{3}$ y José M. Ramirez-Scarpetta ${ }^{4}$
}

Recibido: 15 de febrero de 2018

Aceptado: 04 de abril de 2018

Cómo citar / How to cite

I. F. Moran, J. A. Restrepo, M. L. Orozco-Gutierrez, y J. M. RamirezScarpetta, Quasi-switched inverter using space vector pulse width modulation with triangular comparison for photovoltaic applications. TecnoLógicas, vol. 21, no. 42, pp. 95-110, 2018.

1 Electronic Engineer, Escuela de Ingeniería Eléctrica y Electrónica, Universidad del Valle, Cali-Colombia, ivan.moran@correounivalle.edu.co

2 PhD. in Electrical Engineering and Electronics, Departamento de Electrónica y Circuitos, Universidad Simón Bolívar, Caracas-Venezuela restrepo@usb.ve. Facultad de Ingeniería en Ciencias Aplicadas, Universidad Técnica del Norte, Ibarra-Ecuador, jarestrepo@utn.edu.ec

$3 \mathrm{PhD}$. in Engineering, Escuela de Ingeniería Eléctrica y Electrónica, Universidad del Valle, Cali- Colombia, martha.orozco@correounivalle.edu.co

4 PhD. in Control Systems, Escuela de Ingeniería Eléctrica y Electrónica, Universidad del Valle, Cali-Colombia, jose.ramirez@correounivalle.edu.co 
Quasi-switched inverter using space vector pulse width modulation with triangular comparison for photovoltaic applications

\section{Abstract}

This work analyzes a prototype of a quasi-switched boost inverter (qSBI) feeding an isolated resistive load from a DC source. The use of spatial vector pulse width modulation (SPWM) with triangular comparison is proposed to increase the qSBI gain factor, and its performance is contrasted with other types of spatial vector modulations, such as discontinuous modulations. To verify the validity of the method for voltage range extension in the qSBI converter, a semi-customized test platform was developed. This platform uses a DSP floating point card (Analog Devices ADSP-21369) for processing and control strategies and an interface card that includes a programmable logic array (FPGA) from Xilinx (Spartan-3), which allows to develop the synchronized modulation qSBI needs. The experimental results show improvements in the performance of the qSBI converter in terms of gain factor, voltage reduction in the capacitor, and input current profiles. Discontinuous space vector modulation strategies do not perform well when compared to continuous SVPWM or SPWM modulations, because the ripple levels in the currents taken from the PV module are approximately twice as great as in continuous modulation techniques. Finally, the usefulness of a qSBI as PV microinverter is confirmed by two practical experimental cases of a PV photovoltaic system with a maximum power point adjustment algorithm (MPPT).

\section{Keywords}

Quasi-Switched Boost Inverter, Space Vector Modulation, Sinusoidal Modulation, Embedded System, PV Microinverter.

\section{Resumen}

Este trabajo analiza un prototipo para un inversor elevador cuasi-conmutado (qSBI) alimentando una carga resistiva aislada desde una fuente de CC. Se propone el uso de una modulación de ancho de pulso de vectores espaciales (SPWM) con comparación triangular que genera un incremento en el factor de ganancia del qSBI, y se contrasta su desempeño con otro tipo de modulaciones de vectores espaciales, tales como las modulaciones discontinuas. Para verificar la validez de la extensión de rango de tensión en el convertidor qSBI, se desarrolló una plataforma de pruebas semi-personalizada. Esta plataforma utiliza una tarjeta DSP de punto flotante (Analog Devices ADSP-21369) para el procesamiento de las estrategias de control, y una tarjeta de interfaz que incluye un arreglo lógico programable (FPGA) de Xilinx (Spartan-3), que permite desarrollar la modulación sincronizada que el qSBI necesita. Los resultados experimentales demuestran mejoras en el desempeño del convertidor qSBI en cuanto al factor de ganancia, reducción del estrés de voltaje en el capacitor y los perfiles de corriente de entrada. Las estrategias discontinuas de modulación del vector espacial no presentan un buen desempeño cuando se compara con las modulaciones continuas SVPWM o SPWM, ya que los niveles de rizado en las corrientes tomadas del módulo PV son de aproximadamente el doble que en el caso de las técnicas de modulación continuas. Finalmente, el uso del convertidor qSBI como microinversor es puesto en evidencia por dos casos experimentales prácticos de un sistema fotovoltaico PV con un algoritmo de ajuste del máximo punto de potencia (MPPT).

\section{Palabras clave}

Inversor Elevador cuasi-Conmutado, Modulación del Vector Espacial, Modulación Senoidal, Sistema Embebido, Microinversor PV. 


\section{INTRODUCTION}

Voltage Source Inverters (VSIs) are an important part for power flow control in electrical vehicles, motor/generator drives, flexible power transmission, and integration of renewable generation units (photovoltaic panels, fuel cells, batteries, etc.) into the grid, among others. In the last two decades, the Z-source inverter (ZSI) and Switched boost inverters (SBI) began to appear in scientific literature for solving some drawbacks of VSIs. One of such drawbacks is that AC output voltage cannot be higher than the available DC source and thus extra power stages are needed for applications demanding higher voltage levels [1]. In 2002 and 2003 Peng [2], proposed the ZSI as a robust alternative to the VSI with the capacity to increase the output voltage. Some important advantages of ZSI include the ability to boost-buck voltage in a single-stage power conversion, allow tolerance to one-leg short circuit, minimize component count and reduce costs. Also, in ZSI converters, the output waveform presents less distortion, mainly because both power devices in a leg can turn on at the same time. Other authors [3] have proposed alternative topologies based on ZSIs. For example, [4] proposes a bidirectional ZSI (BZSI), in which a bidirectional switch replaces the input diode. The BZSI admits bidirectional power exchange between AC and DC. Meanwhile, an improved ZSI (IZSI) [5] uses the same elements found in the original ZSI, but in different positions, thus allowing a decrease in the capacitor's voltage stress. On the other hand, the quasi-resonant softswitching Z-source inverter (QRSSZSI) [6] adds a quasi-resonant network for softswitching and it increases the overall efficiency of the converter. Other extended topologies use switched inductor and/or capacitor circuits that increase the boost capacity and power density, which results in increased complexity. The ZSI converter has been the basic topology for other con- verters [3] that always aim at single stage conversion and buck-boost characteristics. Another objective of ZSI-based converters is to decrease the size of passive components, reduce leakage current in the system, and improve output voltage quality, among others. On the other hand, the switched boost inverter (SBI) proposed in [7] uses less passive components than the ZSI and one more active switch. Besides, it fits better in low power applications such as photovoltaic (PV) systems and micro grids.

Photovoltaic (PV) solar energy use has experienced an exponential increase in the last decade. The growing results of PV applications are mainly due to changes in energy and environmental policies, optimization of manufacturing processes of $\mathrm{PV}$ panels and power electronic devices, and new research on materials and electronic devices, among others. In PV systems, mismatching produced by shadows, aging and tolerances in manufacturing, result in large power losses. Recently, panel reconfiguration and distributed power processing (DPP) systems have shown promising results to overcome the limits imposed by mismatching [8]. DPP systems use power electronics solutions dedicated to small portions of the PV array, usually a string or single panel (microinverter). In PV microinverters, there is a panel associated with a power converter. The converter must have a high boost factor because the voltage range in commercial PV panels is low, typically between $20 \mathrm{~V}$ to $40 \mathrm{~V}$. An advantage of inverter-per-panel DC-AC power conversion is the capacity to extract the maximum available power from each panel by using a MPPT algorithm in the DC-to-DC stage. Moreover, PV microinverters allow for plug-and-play connectivity to the grid. Therefore, PV systems based on this technology are scalable and the impact of faults is lower than in centralized or string configurations. Additionally, the decrease in power management reduces the demands on the DC wire [9]. How- 
ever, a disadvantage of PV microinverters is the installation cost, as they require as many microinverters as panels. Also, the number of power converters with nonunitary efficiency affects the installation's power harvesting. On the other hand, string configurations use a DC-to-DC converter for a group of PV panels, thus reducing the boost voltage factor in comparison with PV microinverter technology. The main weakness of string configuration is the reduced robustness under mismatching conditions. Additionally, typical string configurations provide a single phase solution on the $\mathrm{AC}$ side. A distribution of the control means that more power converters with higher efficiency and voltage boost are needed. For this type of applications, the previously mentioned ZSI and SBI converters seem to be suitable solutions.

The Quasi-Switched Boost Inverter (qSBI) belongs to the class of SBI topologies. The qSBI has low capacitor voltage in a dc-linked type, with high boost voltage and continuous input current [1]. Previous studies by other authors present complete analyses of the qSBI [1],[10]. This work implements a modulation technique for space vector PWM to increase the boost voltage factor of the qSBI converter, which makes it suitable to be used in PV microinverters. This paper is organized as follows: Section two explains the general performance of a qSBI. Section three details the PWM control techniques and describes the experimental prototype. Section 4 presents the experimental results using a fixed DC source as well as a DC source based on a single PV panel and string configuration. The paper ends with conclusions and future works.

\section{2. qSBI TOPOLOGY}

The topology of a qSBI converter has higher efficiency and boost gain than common boost converters (Fig.1) [1]. Such topology uses one more active switch in comparison with others boost inverters, such as the ZSI, but it requires less passive components. Additionally, the qSBI can provide a continuous input current.

As shown in Fig.1, a qSBI converter is essentially formed by two cascaded power stages, a boost DC/DC stage and a VoltageSource Inverter (VSI) stage. When the VSI outputs space vectors zero $\left(\overrightarrow{v_{0}}\right.$ or $\overrightarrow{v_{7}}$ in Fig.2), the voltage in the DC bus $\left(V_{p n}\right)$ has no effect on these vectors' value. This opens the possibility of using the VSI to establish a path for energy storage in the boost inductance $L_{a}$, an operating condition

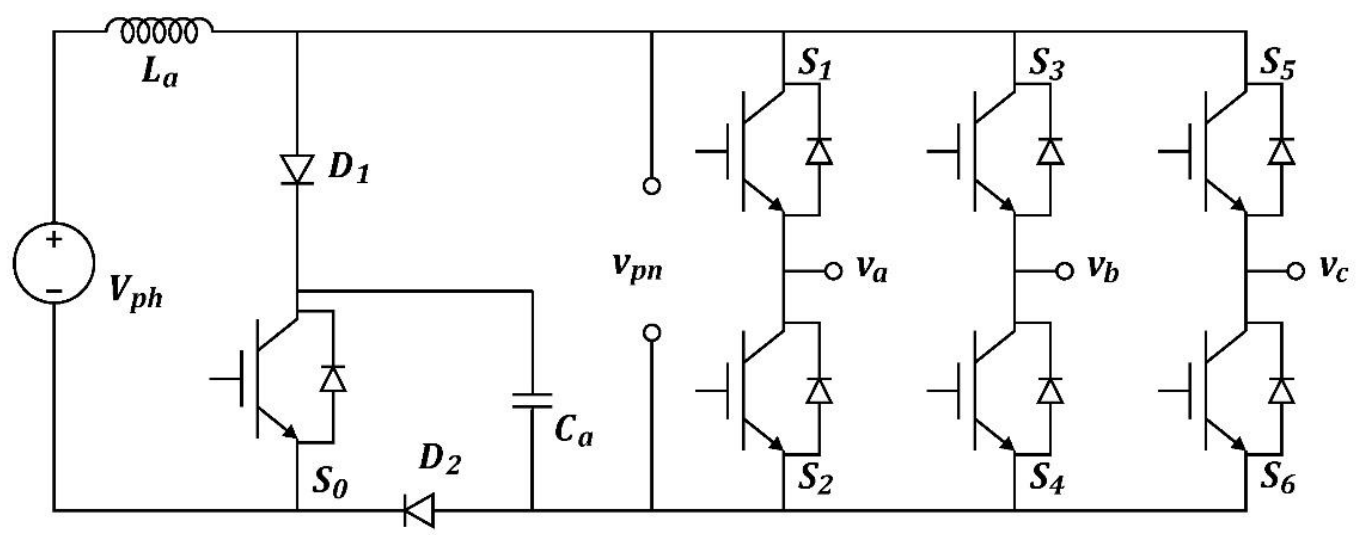

Fig. 1. One-line diagram of the Three-Phase quasi-Switched Boost Inverter. Source: authors. 
known as shoot-through state. While the VSI puts out space vectors zero, the shootthrough state uses any VSI leg while switching $S_{0}$ to feed the boost inductance from the PV generator. This stores energy in inductance $L_{a}$, as described above, and at the same time capacitor $C_{a}$ discharges into the load. The other state (non-shootthrough state) occurs when switch $S_{0}$ opens while removing the VSI short-circuit. During the non-shoot-through state, inductor $L_{a}$ transfers energy from the DC voltage source $\left(V_{p h}\right)$ to the load and to capacitor $C_{a}$.

Fig. 3 shows the equivalent circuits for the two qSBI's stable states, where $r_{S}$ is the power devices' resistance; $r_{L}$ and $r_{C}$, the parasitic resistance of the inductor and the equivalent series resistance (ESR) of the capacitor; $i_{0}$, the current in the load; $\mathrm{R}$, the load; and $r_{D}$, the diode's resistance. Diodes $D_{1}$ and $D_{2}$ do not conduct during the shootthrough state, while switch $S_{0}$ turns on and the VSI closes the path by turning on all its (high side and low side) power devices, which results in the equivalent circuit shown in Fig.3a. On the other hand, diodes $D_{1}$ and $D_{2}$ conduct during the non-shoot- through state, while the VSI does not close the path and switch $S_{0}$ is off, which results in the equivalent circuit shown in Fig. $3 \mathrm{~b}$.

The two stable operating states provide the equations describing the circuit's operation and the capacitor's voltage $V_{c a}$ as a function of the input voltage $V_{p h}$ and duty cycle $D$ [1][10]:

$$
\mathrm{V}_{\mathrm{c} a}=\frac{1}{1-2 D} V_{p h}
$$

The voltage ratio between $V_{c a}$ and $V_{p h}$ indicates the converter's voltage gain. Since the overall circuit operation, shootthrough and non-shoot-through states depend on the duration of the VSI's zero state, the duty cycle in (1) bounds the VSI modulation index $M$. Therefore, the time allotted for the non-zero space vectors plus the time for the shoot-trough state should not exceed the modulator's carrier period. According to (1), the ideal converter's gain becomes undetermined for $D=0.5$. This imposes a practical low limit for the modulation index value of $M_{B L}=0.5$.

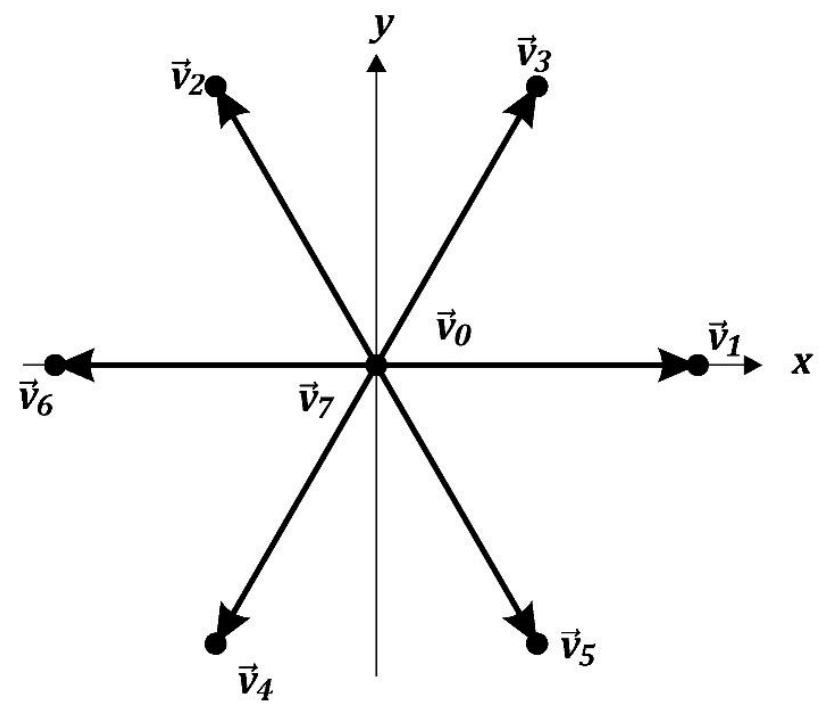

Fig. 2. Space vectors in the voltage source inverter (VSI). Source: authors. 


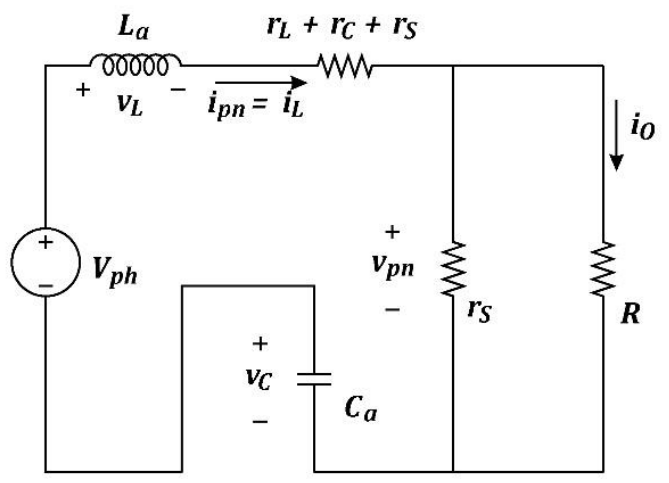

(a) Shoot-through state.

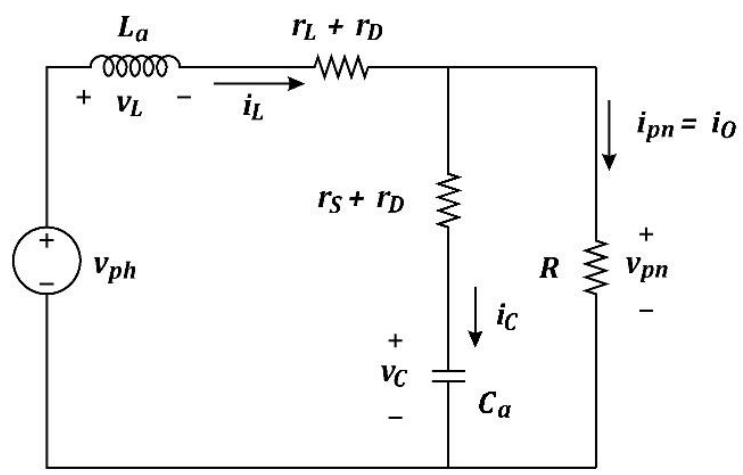

(b) Non shoot-through state.

Fig. 3. qSBI stable operating states. Source: [1]

\section{PWM CONTROL OF qSBIS}

This work uses the triangular comparison method for implementing the generalized space vector modulation [11],[12],[13]. Fig. 4 shows an example of the PWM pulses generated by test duty cycle demands in phases $a, b$ and $c$, where $V_{c c}$ is approximately equal to the capacitor's voltage $v_{c}$. The zero vectors in Fig.4 appear spread in three different regions. From the start of the switching period to $t_{1}$, they are associated with zero vector $\overrightarrow{v_{7}}$; from $t_{3}$ to $t_{4}$, with $\overrightarrow{v_{0}}$; and from $t_{6}$ to the end of the switching period, with $\overrightarrow{v_{7}}$. It is clear from Fig.4 that nonzero space vectors $\left(\overrightarrow{v_{1}}\right.$ to $\left.\overrightarrow{v_{6}}\right)$ are active between instants $t_{1}$ and $t_{3}$ and between $t_{4}$ and $t_{6}$. The extreme duty cycles $D_{\max }$ and $D_{\text {min }}$ define the previous time slices, employed later by the qSBI modulation method.

Fig. 5 shows the time distribution of the PWM carrier signal. The duty cycle requires sinusoidal modulation for the three phases of the VSI and the duty cycle, for the shoot-though states $\left(D_{L}\right.$ and $\left.D_{H}\right)$. The references of the duty cycle for the shootthrough states also provide a visual representation of the VSI's maximum modulation index. 


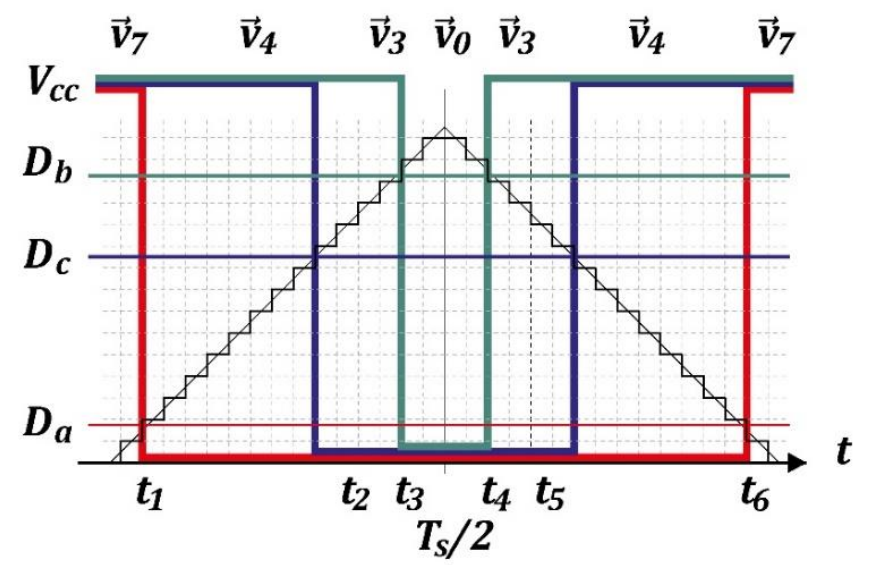

Fig. 4. PWM pulses generated using the triangle comparison method. Source: [13].

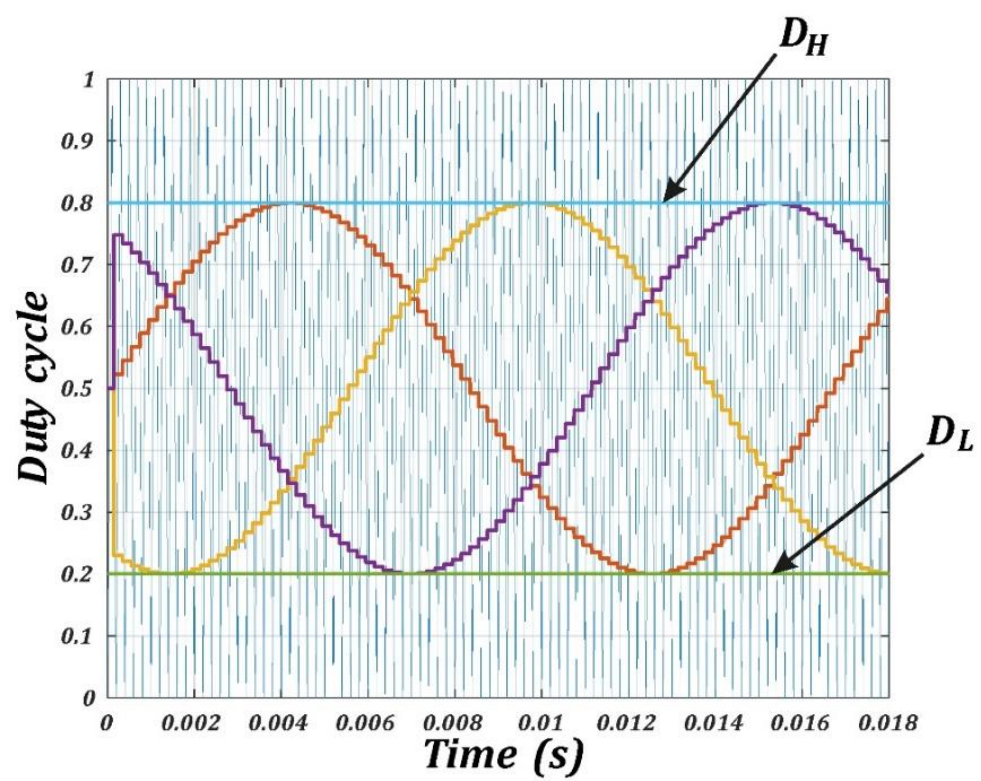

Fig. 5. Modulation and Carrier signals in PWM by triangle comparison for sinusoidal modulation and boost references. Source: authors.

\subsection{Experimental qSBI test rig}

The carrier for the PWM synchronizes the acquisition (current and voltage) and the controller's execution cycle. For the qBSI, this synchronization allows the correct operation of the shoot-through and non-shoot-through states, as shown in Figs. 4 and 5. Hence, a prototype board housing an FPGA provides the means to integrate the PWM module and the temporal synchronization with the qSBI's shoot-through pulses. There are other tasks incorporated in the FPGA, such as $\mathrm{AD}$ controlling and allowing data exchange between sensor boards and the processing unit (digital signal processor, DSP).

This work proposes a noninvasive change in the existing PWM hardware for producing the "on-off" commands feeding the power switches. The original PWM pulse generation remains unchanged, while new pulses are synthesized for controlling the shoot-through states. To this end, two extra duty cycle demands $D_{L}$ and $D_{H}$ generate extra gating signals $g_{L}$ and $g_{H}$ 
used to control switch $S_{0}$ and to change the signals going to the VSI's power switches, as shown in Fig. 4. The conventional PWM puts out the trigger signals $g_{1}$ to $g_{6}$, plus $g_{L}$ and $g_{H}$ used to change the gate signals going to the VSI in Fig.1. The new gate signals $\overline{g_{k}}$ follow the logic rule described in (2) and (3). Fig. 6 shows the modified gate signals, created with the original gated signal and the boost duty cycle demands, in accordance with (2) and (3):

$$
\begin{gathered}
g_{\mathrm{s} 0}=g_{L}+\bar{g}_{H} \\
\bar{g}_{k}=g_{k}+g_{s 0}, \forall k=1 \text { to } 6
\end{gathered}
$$

Where + denotes the logic or operator. This way, all the power devices turn on during the shoot-through state.

\subsection{PWM control techniques for the qSBI}

The boost gain versus the maximum modulation index in the qSBI topology sets a limit to its use. In turn, such limit imposes a compromise between modulation index and boost gain to supply maximum voltage to the load. Once the user fixes the boost stage gain, any extra gain for the qSBI should come from the modulation technique used in the voltage source inverter (VSI). For three-phase systems, sinusoidal and space vector PWM are the most widely-used modulation techniques. However, the qSBI needs a coordinated switching of the boost stage and the VSI, as previously described. SV PWM allows the SVI to synthesize space vectors $15.47 \%$ larger than the ones from sinusoidal PWM.

The use of standard triangular comparison SV PWM solves the synchronization problem. From Figs. 5 and 7, it is clear that standard SV PWM does not need any change in the duty cycle demand for the shoot-through states.

However, there are more possible candidates for SV PWM [14]. Among them, the discontinuous form is a special type [15],[12]. $D P W M_{\max }, D P W M_{\min }, D P W M_{0}$, $D P W M_{1}, D P W M_{2}, \quad D P W M_{3}$ comprise the most commonly-used discrete space vector modulation techniques. Modulation methods $\left(D P W M_{0-3}\right)$ need a complex switching selection to synchronize the boost stage with the VSI stage, while the $D P W M_{\min }$

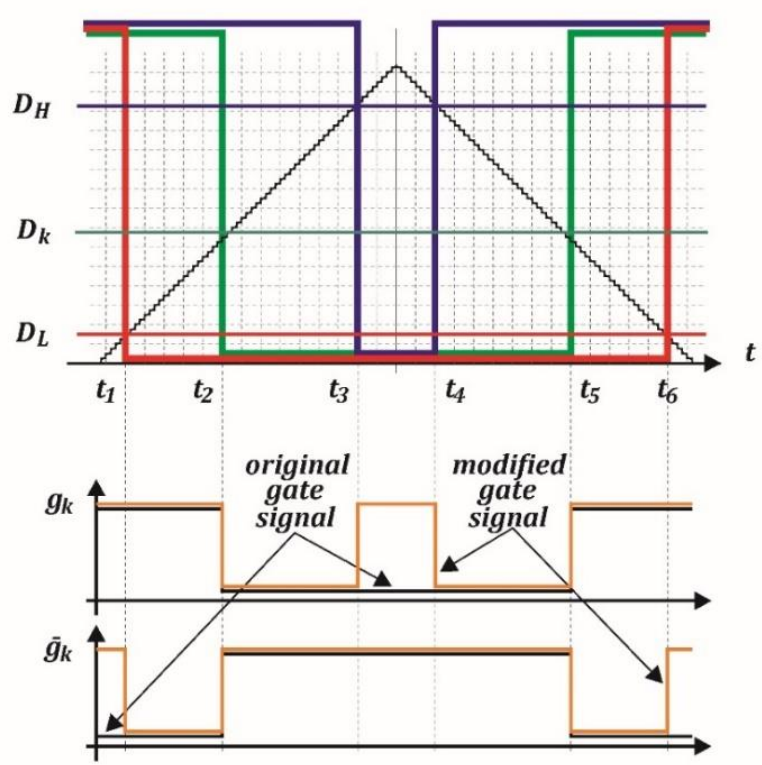

Fig. 6. Gate signal modified with the boost duty cycle demands. Source: authors. 

applications

and $D P W M_{\max }$ with the VSI stage, while the $D P W M_{\min }$ and $D P W M_{\max }$ methods use a simpler duty cycle demand. For example, when the $D P W M_{\text {min }}$ method is adopted, the $S_{0}{ }^{\prime} S$ commutation frequency halves. This means that the current charge and discharge cycle takes more time and the inductance current ripple increases, as shown in Fig.8. As a result, the ripple current is higher for discrete modulations, while the continuous modulation methods result in smaller ripple in the inductor current, shown in Fig. 8. Therefore, it is more likely that a converter starts working in a discontinues zone. In the discontinuous operation equation (1), it is not valid to evaluate the boost voltage gain or the capacitor voltage. No experimental test will be presented for discontinuous modulation methods.

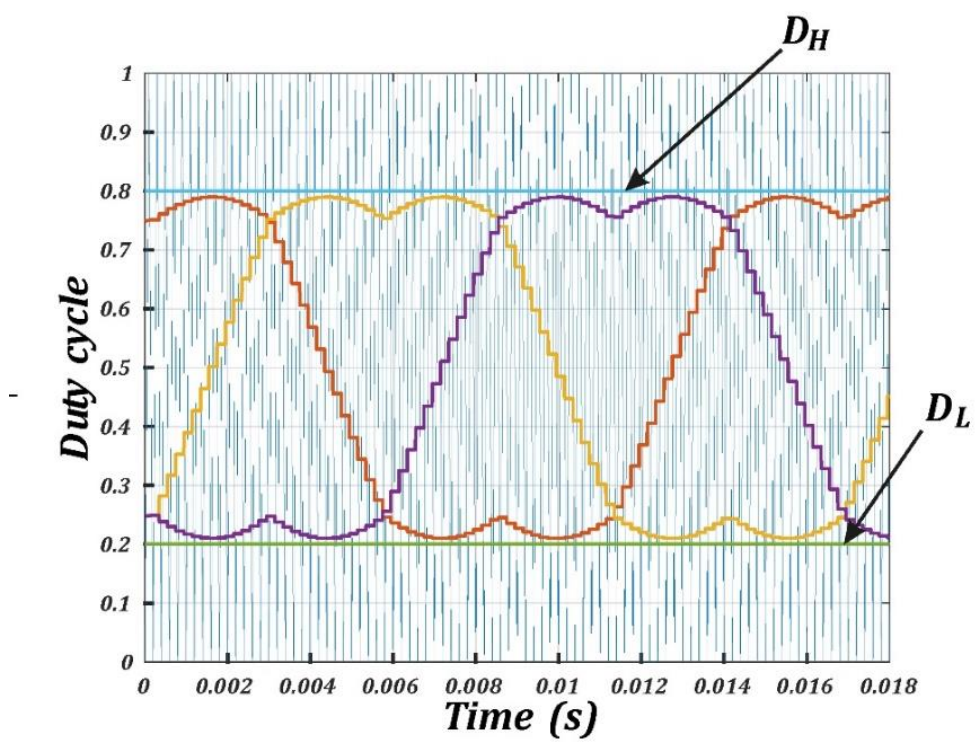

Fig. 7. Modulation and Carrier signals in PWM by triangle comparison for space vector modulation and boost references. Source: authors.

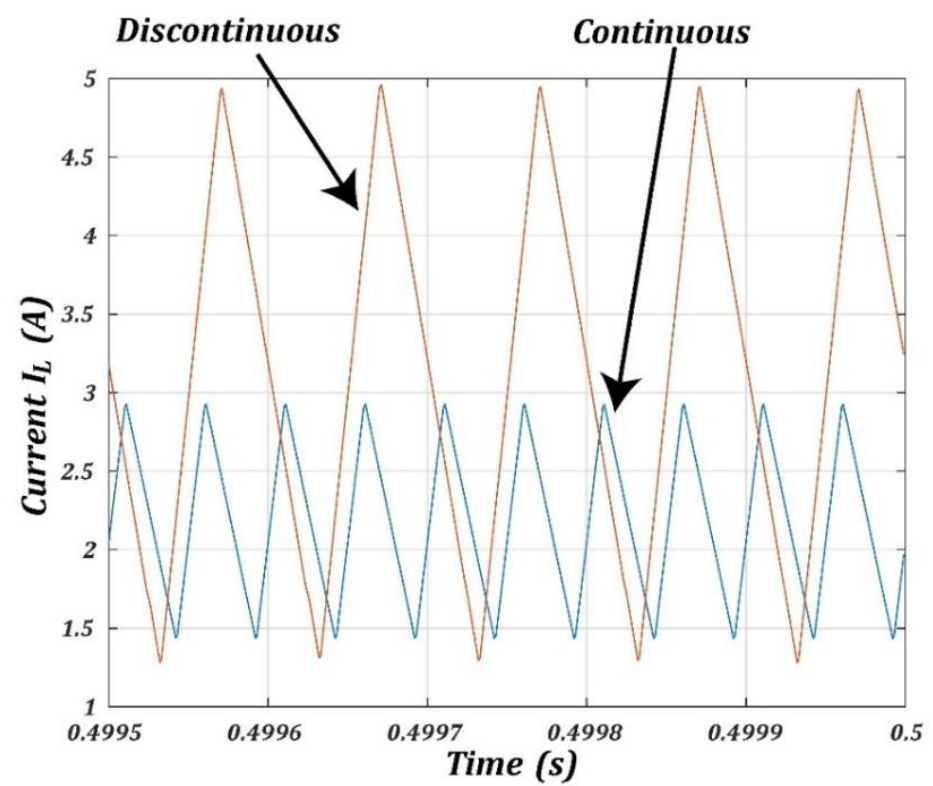

Fig. 8. Inductance current comparison for operation using SVM vs $D P W M_{\min }$. Source: authors. 


\section{EXPERIMENTAL VALIDATION}

Fig.9 shows the experimental prototype used in this work. The power stage uses seven switches and two diodes mounted on four heat-sink columns. The driver for the IGBT switches sits on top of the heat-sinks to minimize the cable's length. The DC link is located in the middle of the equipment, with the capacitor placed on the left. The sensor board, placed in the lower part of the setup, allows to record the control variables for the inverter and quasi-boost converter.

The processing unit is based on a digital signal processor (DSP) that provides the necessary processing power to execute complex computational tasks. The test rig in this work uses an Analog Devices DSP of the SHARC family (ADSP-21369).

This section shows the qSBI experimental validation for three practical cases. The first test uses a DC source to show the qSBI's basic performance. The other two tests use a PV source controlled with an
MPPT algorithm. One uses a single PV panel, which reveals the need for high boost factor and high efficiency in distributed applications. The other PV test uses a PV string feeding the qSBI and has the advantages of using SVPWM instead of the common SPWM.

\subsection{Experimental test using a DC Source}

Fig.10 shows the steady state behavior of the capacitor, inductor and DC bus of the qSBI converter. When switch $S_{0}$ of Fig. 1 is turned OFF, the voltage in the DC bus of the inverter (CH-2 in Fig.10) is equal to the capacitor's voltage $(\mathrm{CH}-1$ in Fig.10). At that instant, the inductor current (CH-3 in Fig.10) has a negative slope, so the current flows to the load. On the other hand, when switch $S_{0}$ is turned $\mathrm{ON}$, the DC bus voltage (CH-2 in Fig.10) is zero. The inductor current (CH-3 in Fig.10) has a positive slope that corresponds to the shoot-through state. In this experiment,

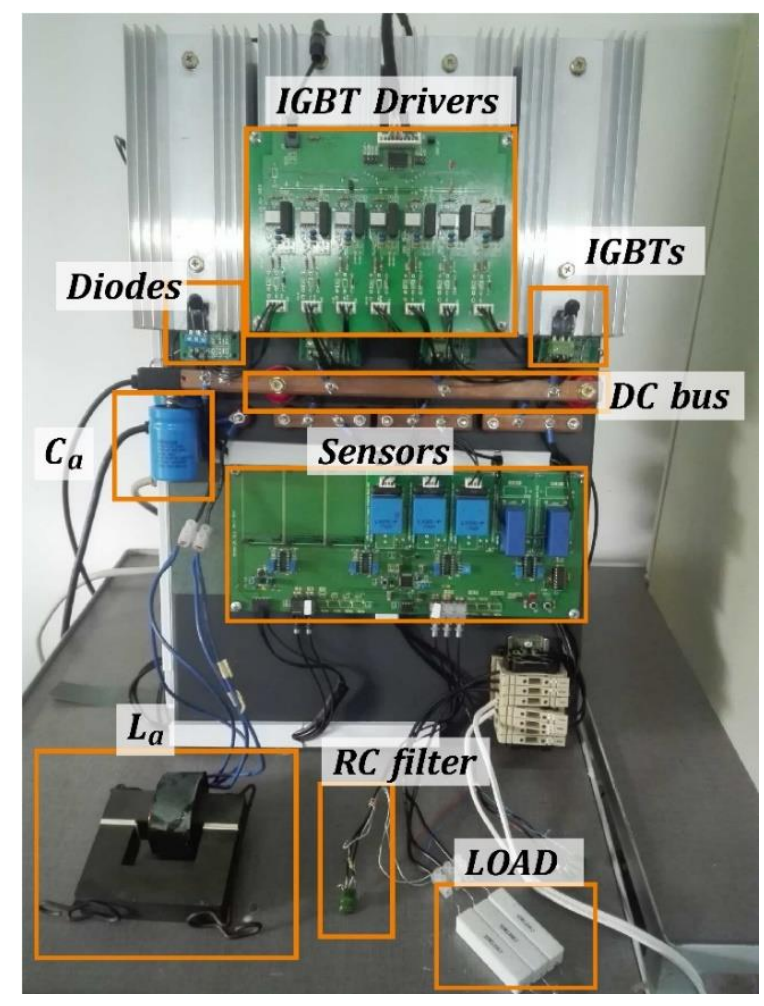

Fig. 9. Experimental prototype for the qSBI. Source: authors. 

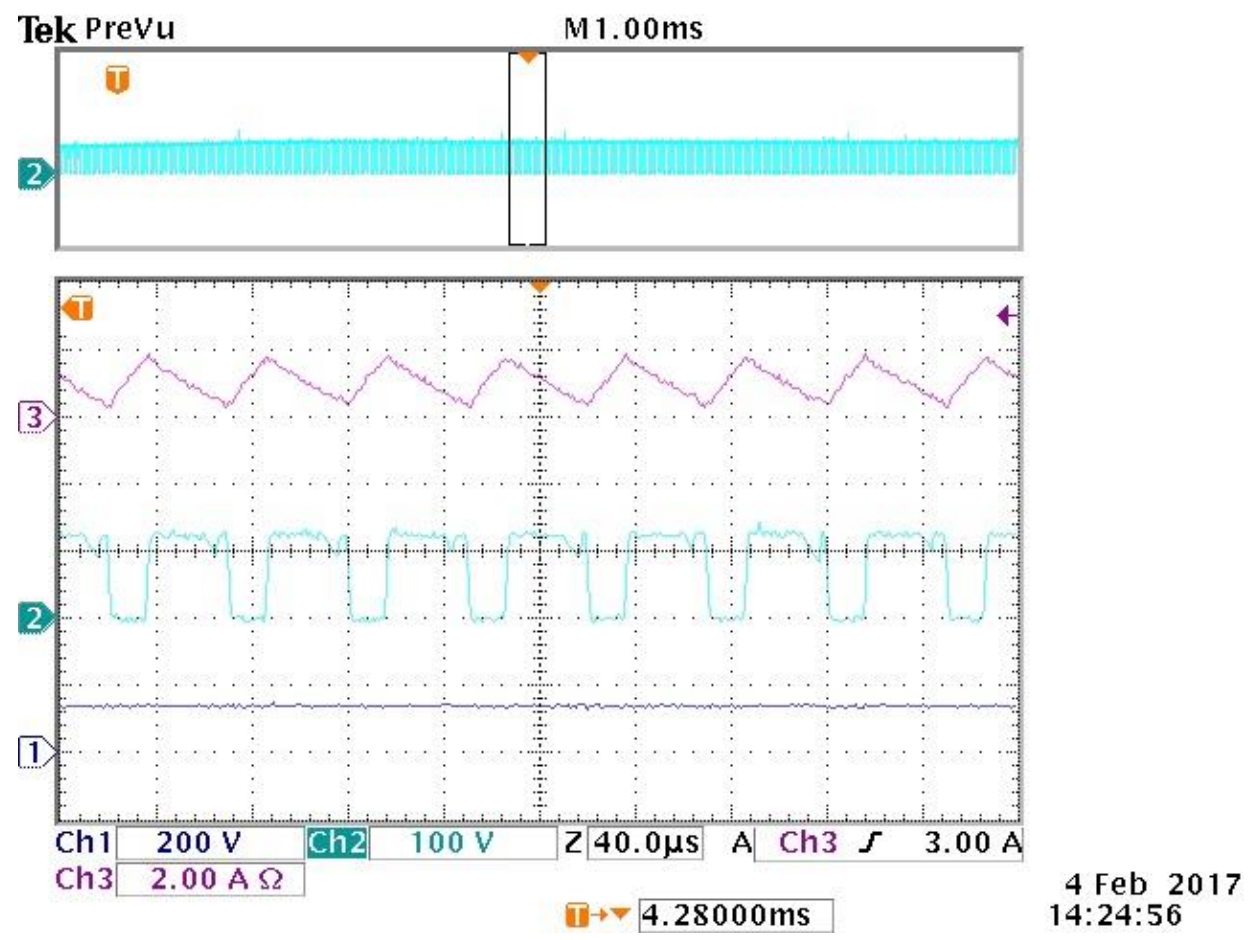

Fig. 10. Experimental waveforms of qSBI (ch1: Capacitor voltage, ch2: DC bus voltage, ch3: Inductor current). Source: Author

the boost factor was 3.3 , which corresponds to $\mathrm{D}$ equal to 0.35 , and the modulation index in the VSI was 0.6.

Figure 11 shows the results for a test using a DC source with higher voltage. The blue signal is the inductor current, the cyan signal is the capacitor voltage and the magenta signal is the output voltage. The qSBI is controlled using a sinusoidal PWM. To avoid high current and voltage overshoots in the converter, the duty cycle is increased in six steps. For measuring purposes, the $V_{a b}$ output voltage is taken from a passive RC filter with a $1 / 3$ gain. This results in a peak output voltage close to 120 V. Figure 12 shows the results when using the previous conditions in DC source and duty cycle steps, but with space vector PWM (SVPWM). As shown by the cursor position in Figs. 11 and 12, the SV PWM technique improves the total boost factor of the qSBI converter. The output voltage increased from $120 \mathrm{~V}$ (SVPWM) to $150 \mathrm{~V}$ (SPWM).

\subsection{Experimental practical test: Extracting Maximum Power from a PV panel}

The improved gain factor of the qSBI and the adoption of a MPPT algorithm are two of the main features of the converter that make it appropriate for PV microinverters. Those characteristics are confirmed in the following two experimental cases. In the first test, the experimental qSBI prototype extracts the maximum power from a PV panel. A basic perturb and observe algorithm (P\&O) [16] implemented in the DSP unit extracts the maximum power from a commercial ERDM85 $\mathrm{PV}$ panel. The $\mathrm{P} \& \mathrm{O}$ continually changes the duty cycle of the qSBI to reach the maximum power point of the PV panel.

The modulation in this experiment is the standard SPWM, the maximum duty cycle is 0.49 , and the modulation index is 0.5 for maximum voltage swing. The changes in $D$, named $\Delta D$ in the $\mathrm{P} \& \mathrm{O}$ algorithm [17], were set to 0.01 , and the perturbation period $T_{p}$ was $50 \mathrm{~ms}$. Fig.13 shows the experimental results extracted 
Quasi-switched inverter using space vector pulse width modulation with triangular comparison for photovoltaic applications

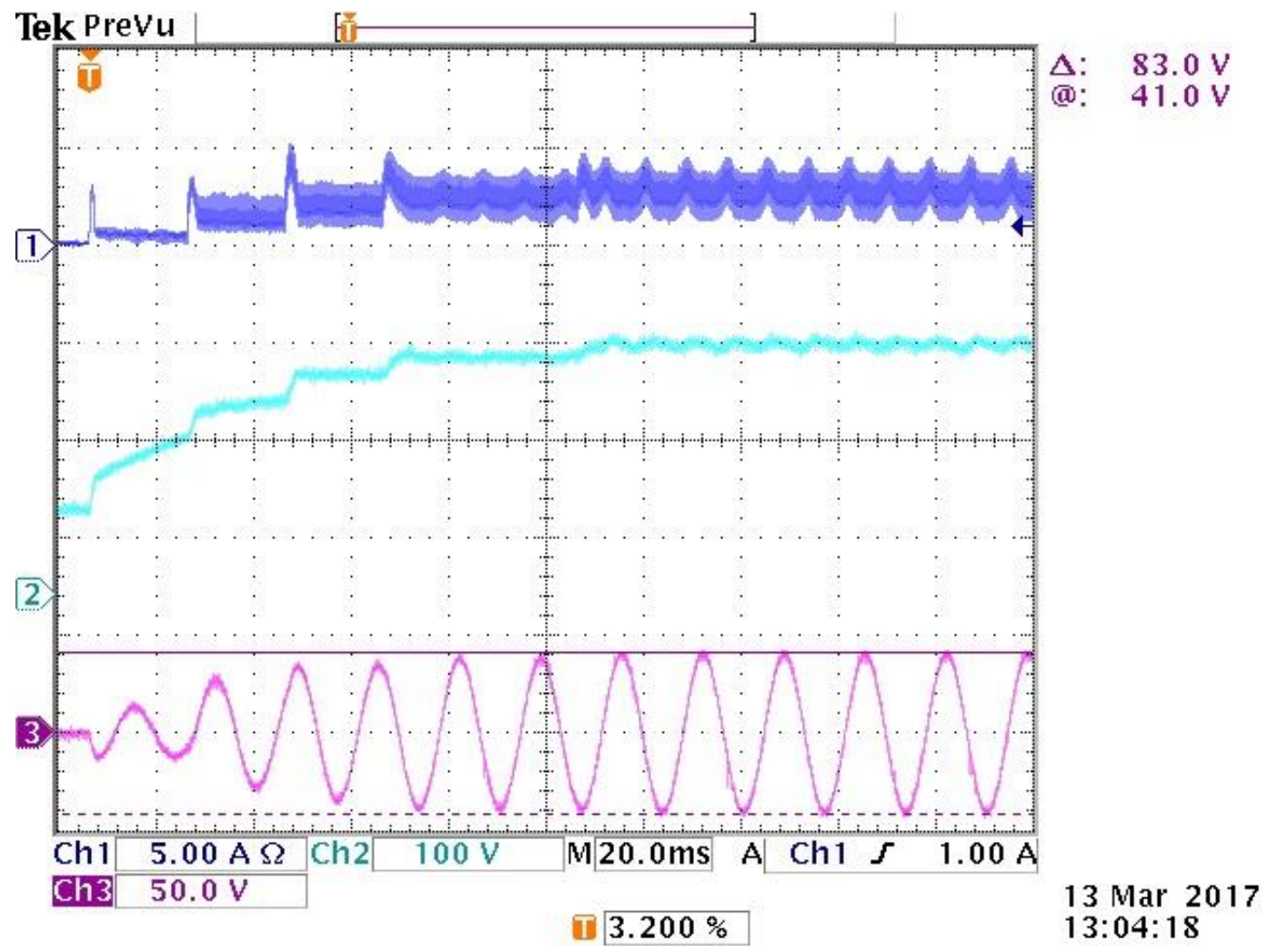

Fig. 11. Experimental waveforms of qSBI for sinusoidal modulation (ch1: Inductor current, ch2: Capacitor voltage, ch3: Low-pass filter voltage). Source: authors

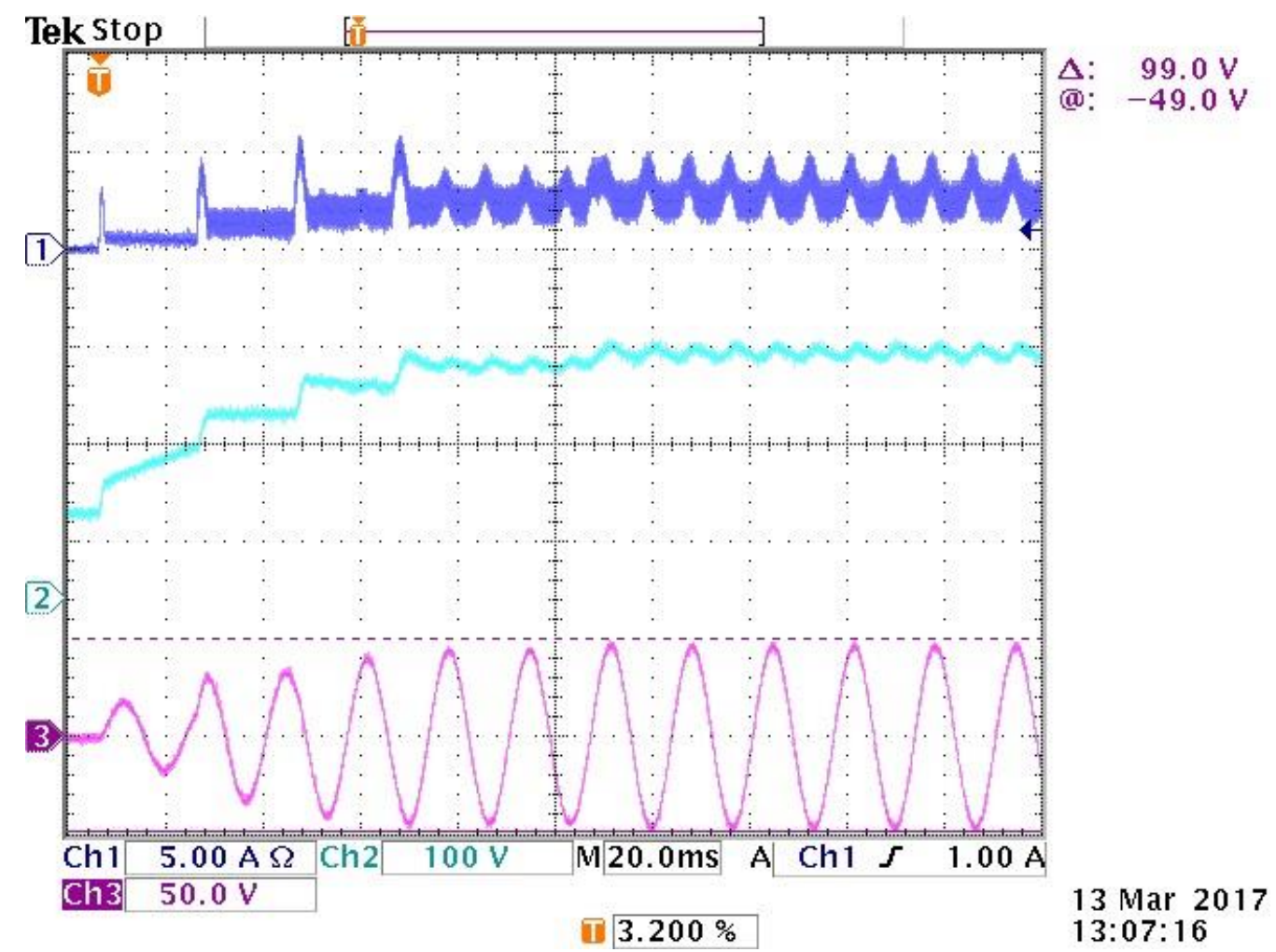

Fig. 12. Experimental waveforms of the qSBI for space vector modulation (ch1: Inductor current, ch2: Capacitor voltage, ch3: Low-pass filter voltage). Source: author's 
from the DSP's external memory. In this figure, the red line corresponds to the duty cycle $D$ of the boost stage. The first part of that curve shows the starting operation, where $D$ increases from 0.125 to 0.31 to avoid current and voltage overshoots in the converter. At $0.7 \mathrm{~s}$, the algorithm reaches the MPP and maintains typical variations

in $D$ around the maximum power. The variation in $D$ produces oscillations in the input power and input voltage of the qSBI, which is evident in the blue and green curves, respectively. Such variations are propagated to the VSI's output voltage, shown in the magenta curve. However, the total boost factor is close to 2.2 .

\subsection{Experimental practical test: Extracting maximum power from a String PV Sys- tem}

The second test with a PV system uses a PV string comprised of four ERDM85 PV panels connected in series feeding the qSBI. This test uses the same basic P\&O algorithm employed in the single PV panel test. However, since the MPP occurs at lower duty cycles, $D$ is limited to 0.39 and the modulation index (using sinusoidal PWM modulation in the VSI) is increased to 0.6. Fig.14 shows the experimental results under these conditions. The red curve shows that the MPP algorithm has faster convergence, in $0.3 \mathrm{~s}$. Also, the duty cycle required to reach the MPP (0.35) is lower than in the case of the single panel. The green curve corresponds to the PV string voltage and the magenta curve, to the output voltage, which results in a 1.7 boost factor.

The final test uses SVPWM, and Fig.15 shows the results. In this case, the duty cycle needed to reach the MPP is around 0.36 , as shown by the red curve. The string voltage, depicted by the green curve, is close to $62.5 \mathrm{~V}$, while the output voltage represented by the magenta curve is $130 \mathrm{~V}$. This shows an increase in the boost factor resulting from the use of the SVPWM in the VSI.
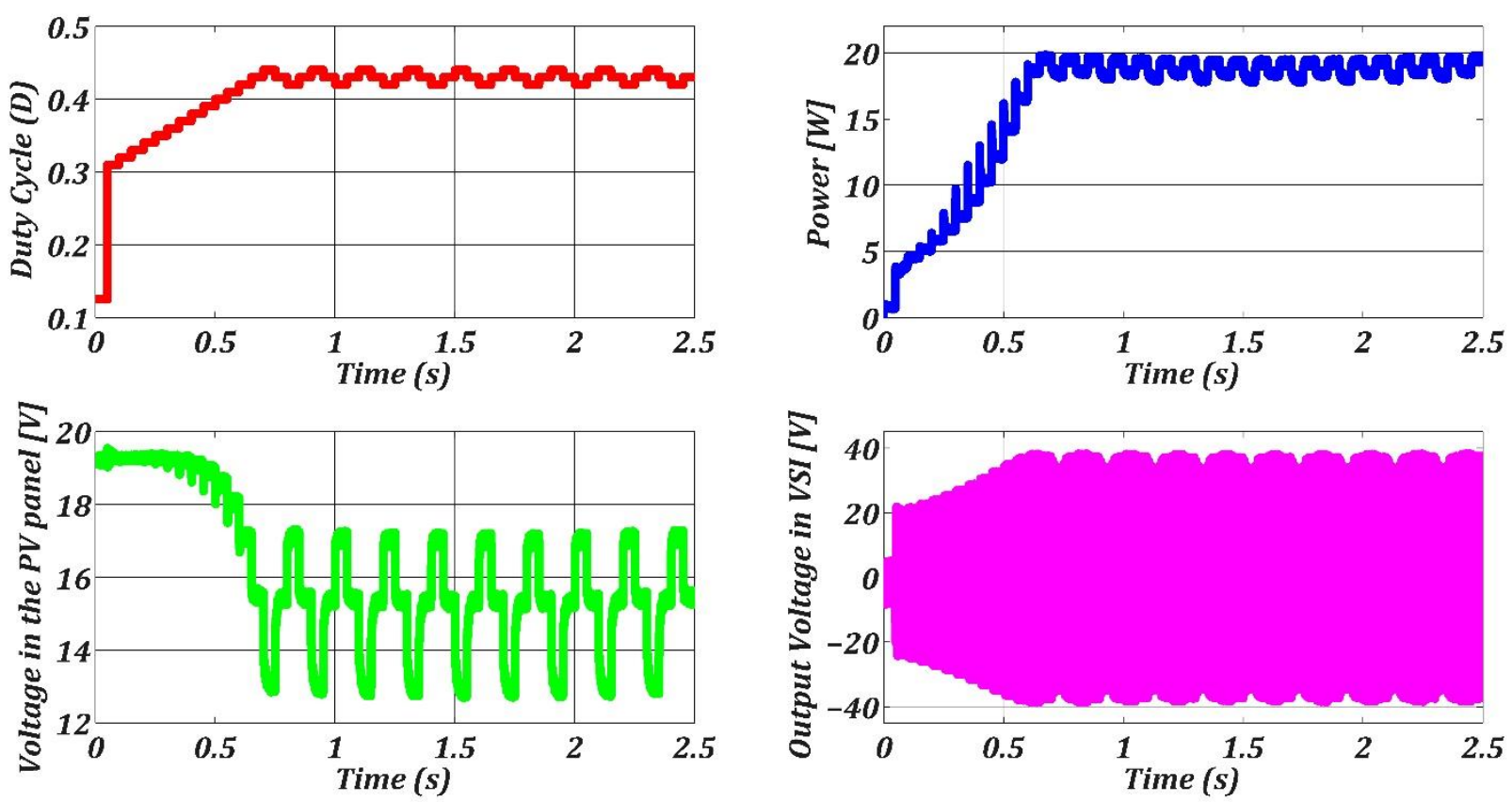

Fig. 13. Experimental results of the qSBI with MPPT algorithm for a PV panel. Source: Author's own work. 

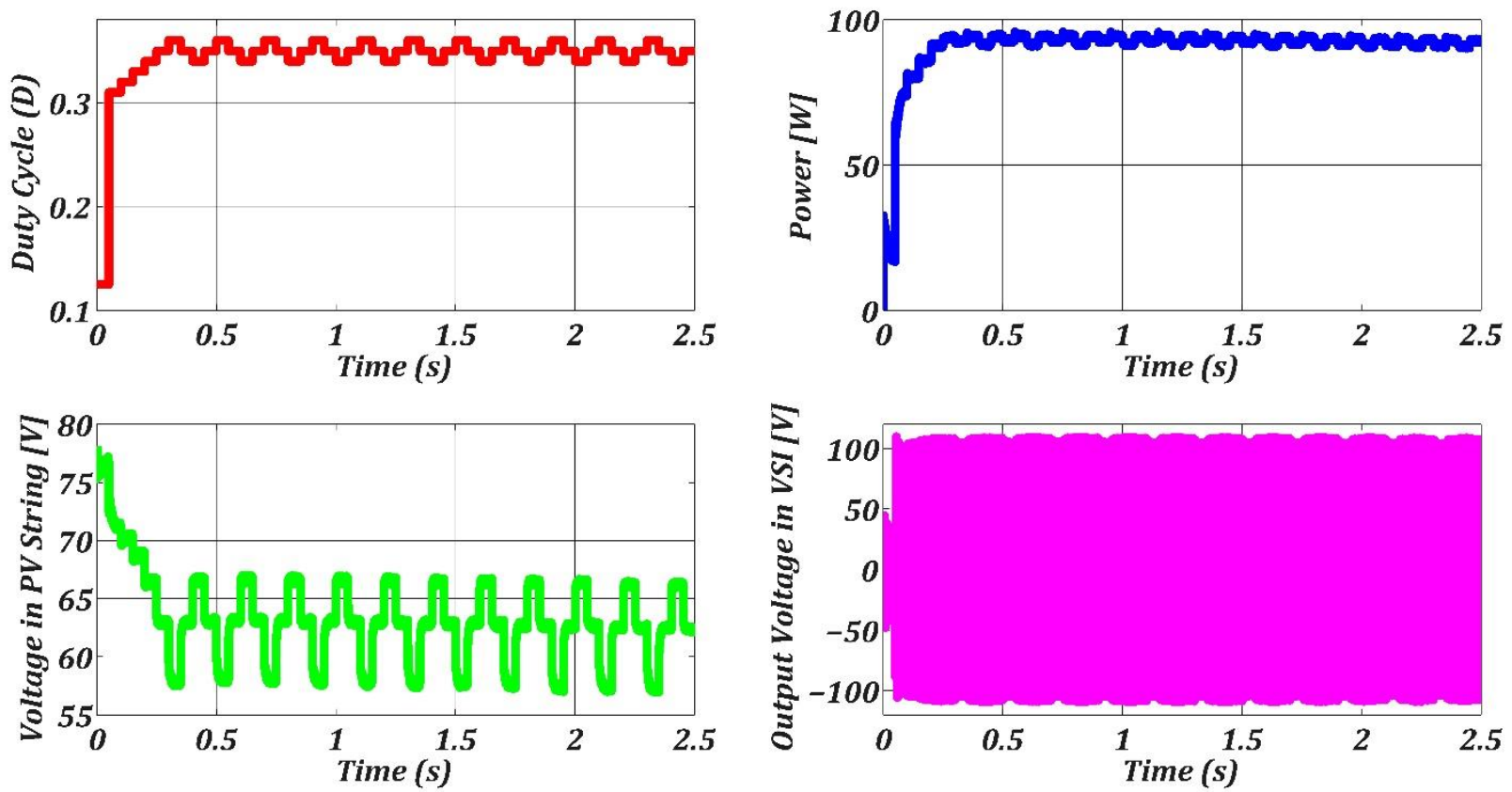

Fig. 14. Experimental results of the qSBI with MPPT algorithm for a PV String. Source: authors.
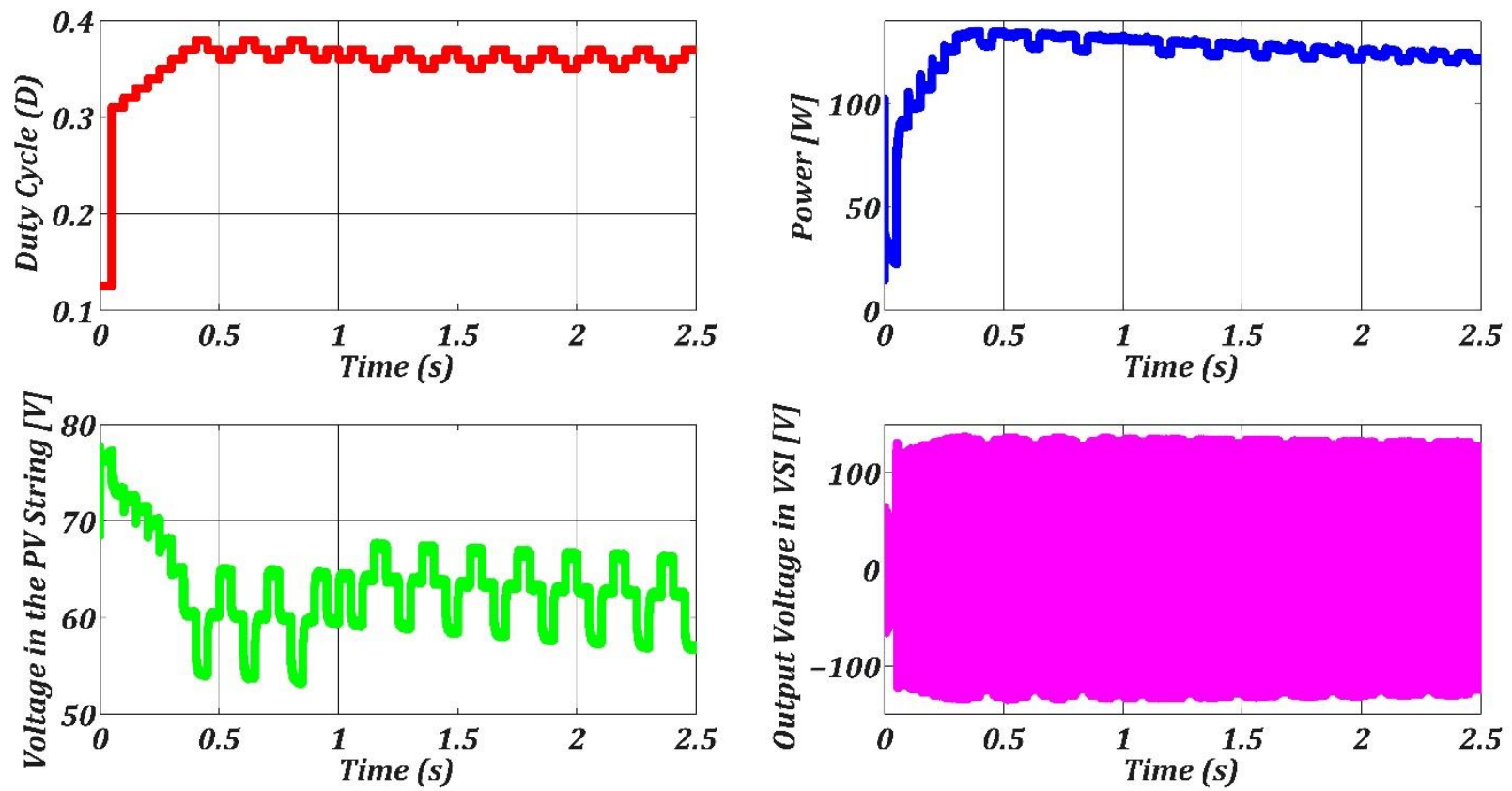

Fig. 15. Experimental results of the qSBI with MPPT algorithm for a PV String and using SV PWM Modulation. Source: authors. 
Quasi-switched inverter using space vector pulse width modulation with triangular comparison for photovoltaic applications

\section{CONCLUSIONS}

In this paper a qSBI experimental prototype has been implemented. Space Vector Pulse Width Modulation (SV PWM) with triangular comparison has been proposed to increase the total boost factor of the converter, which is needed for recent applications such as PV microinverters in distributed PV systems where a single or few PV panels feed the converter. The qSBI prototype employed in this work uses a DSP and FPGA technology that enables the synchronization needed by the modulation method. In PV applications, when MPPT algorithms are used for harvesting power, some oscillations are present in the output voltage. Therefore, more complex MPP algorithms are required to mitigate this undesirable behavior. That will be the aim of future works.

\section{ACKNOWLEDGMENTS}

This work was supported by Universidad del Valle under Project 2823, and Departamento Administrativo de Ciencia, Tecnología e Innovación-Colciencias (Colombia) under contract FP-501-2014.

\section{REFERENCES}

[1] M.-K. Nguyen, T.-V. Le, S.-J. Park, and Y.-C. Lim, "A Class of Quasi-Switched Boost Inverters," IEEE Trans. Ind. Electron., vol. 62, no. 3, pp. 1526-1536, Mar. 2015.

[2] F. Z. Peng, "Z-source inverter," in Conference Record of the 2002 IEEE Industry Applications Conference. 37th IAS Annual Meeting (Cat. No.02CH37344), 2003, vol. 2, no. 2, pp. $775-781$.

[3] O. Ellabban and H. Abu-Rub, "Z-Source Inverter: Topology Improvements Review," IEEE Ind. Electron. Mag., vol. 10, no. 1, pp. 6-24, Mar. 2016.

[4] J. Rabkowski, "The bidirectional Z-source inverter as an energy storage/grid interface," in EUROCON 2007 - The International Conference on Computer as a Tool, 2007, pp. 1629-1635.
[5] Yu Tang, Shaojun Xie, Chaohua Zhang, and Zegang $\mathrm{Xu}$, "Improved Z-Source Inverter With Reduced Z-Source Capacitor Voltage Stress and Soft-Start Capability," IEEE Trans. Power Electron., vol. 24, no. 2, pp. 409-415, Feb. 2009.

[6] Y. Zhu, M. Chen, X. Lee, and Y. Tsutomu, "A novel quasi-resonant soft-switching Z-source inverter," in 2012 IEEE International Conference on Power and Energy (PECon), 2012, pp. 292-297.

[7] S. Mishra, R. Adda, and A. Joshi, "Inverse watkins-johnson topology-based inverter," IEEE Trans. Power Electron., vol. 27, no. 3, pp. 1066-1070, 2012.

[8] G. Spagnuolo, G. Petrone, B. Lehman, C. A. Ramos Paja, B. L. Ye Zhao, and M. L. Orozco Gutierrez, "Control of Photovoltaic Arrays: Dynamical Reconfiguration for Fighting Mismatched Conditions and Meeting Load Requests," IEEE Ind. Electron. Mag., vol. 9, no. 1, pp. 62-76, Mar. 2015.

[9] D. M. Scholten, N. Ertugrul, and W. L. Soong, "Micro-inverters in small scale PV systems: A review and future directions," in 2013 Australasian Universities Power Engineering Conference (AUPEC), 2013, pp. $1-6$.

[10] M.-K. Nguyen, Y.-C. Lim, and S.-J. Park, "A Comparison Between Single-Phase Quasi- ZSource and Quasi-Switched Boost Inverters," IEEE Trans. Ind. Electron., vol. 62, no. 10, pp. 6336-6344, Oct. 2015.

[11] V. Blasko, "Analysis of a hybrid PWM based on modified space-vector and trianglecomparison methods," IEEE Trans. Ind. Appl., vol. 33, no. 3, pp. 756-764, 1997.

[12] J. Restrepo, Víctor Guzmán, M. Giménez, A. Bueno, and J. Aller, "Parallelogram Based Method for Space Vector Pulse Width Modulation," Rev. Fac. Ing. Univ. Antioquia, no. 52, pp. 161-171, 2010.

[13] J. Restrepo, J. M. Aller, A. Bueno, V. M. Guzmán, and María I. Giménez, "Generalized algorithm for pulse width modulation using a two-vectors based technique," EPE J., vol. 21, no. 2, pp. 30-39, 2011.

[14] K. Zhou and D. Wang, "Relationship between space-vector modulation and three-phase carrier-based PWM: a comprehensive analysis," IEEE Trans. Ind. Electron., vol. 49, no. 1, pp. 186-196, 2002.

[15] A. M. Hava, R. J. Kerkman, and T. A. Lipo, "A high-performance generalized discontinuous PWM algorithm," IEEE Trans. Ind. Appl., vol. 34, no. 5, pp. 1059-1071, 1998.

[16] T. Esram and P. L. Chapman, "Comparison of Photovoltaic Array Maximum Power Point 
Quasi-switched inverter using space vector pulse width modulation with triangular comparison for photovoltaic applications

Tracking Techniques," IEEE Trans. Energy Convers., vol. 22, no. 2, pp. 439-449, 2007.

[17] P. Manganiello, M. Ricco, G. Petrone, E. Monmasson, and G. Spagnuolo,
"Optimization of Perturbative PV MPPT Methods Through Online System Identification," IEEE Trans. Ind. Electron., vol. 61, no. 12, pp. 6812-6821, Dec. 2014. 